\title{
The First Planetarium Under Kenyan Skies
}

\author{
Susan Murabana brought to life East Africa's first permanent planetarium \\ using bamboo-a model she hopes will help others build affordable and \\ environmentally friendly planetariums in Africa and beyond.
}

By Erika K. Carlson

E arlier this year, East Africa got its first permanent planetarium. The planetarium, which was built in Nairobi, Kenya, is also sustainable, having been built using locally harvested bamboo. Susan Murabana, president of the recently established African Planetarium Association, spearheaded the building's design and construction along with her partner. The pair are co-founders of the Travelling Telescope, an astronomy outreach effort based in Kenya that uses a portable telescope and an inflatable, mobile planetarium to engage school children throughout the region in astronomy. They were awarded half of the 2020 Europlanet Prize for Public Engagement for their work.

Murabana was inspired to work in astronomy outreach when, as

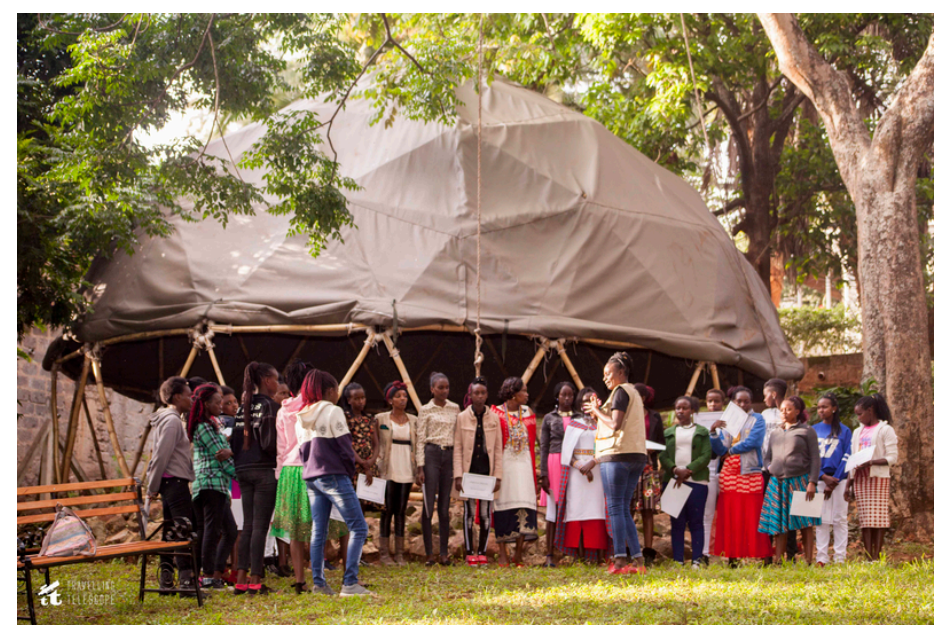

Credit: D. C. Owen/The Travelling Telescope an adult, she met a group of students doing science outreach activities throughout Africa and was reminded of her childhood love for science. In an interview with Physics, Murabana explains the process of bringing the planetarium to life and what it means to her to have built a planetarium in her home country.

All interviews are edited for brevity and clarity.

\section{What inspired you to build the Nairobi Planetarium?}

When my partner and I started the Travelling Telescope, there was a lot of interest from children but also from adults. Visiting schools was sometimes difficult because we had to deal with tight school schedules and the bureaucracy of getting permission to visit. So we thought it would be nice to have a permanent planetarium that anyone could visit.

\section{Why did you choose bamboo as the building material?}

Our headquarters happen to be surrounded by a lot of bamboo, which gave us the idea of using that as a building material. Building a planetarium is costly, but using bamboo meant that we could cut costs. We also thought a bamboo planetarium might be easy for others to replicate, either in Africa or elsewhere.

For me it was important that we build the structure from local materials to reduce our environmental impact. As a young girl, I absolutely admired Professor Wangari Maathai, the first Nobel Prize winner from Kenya, who fought for the environment. I think many Kenyans remember her struggles. I wanted the planetarium to demonstrate dedication to the environment too. 


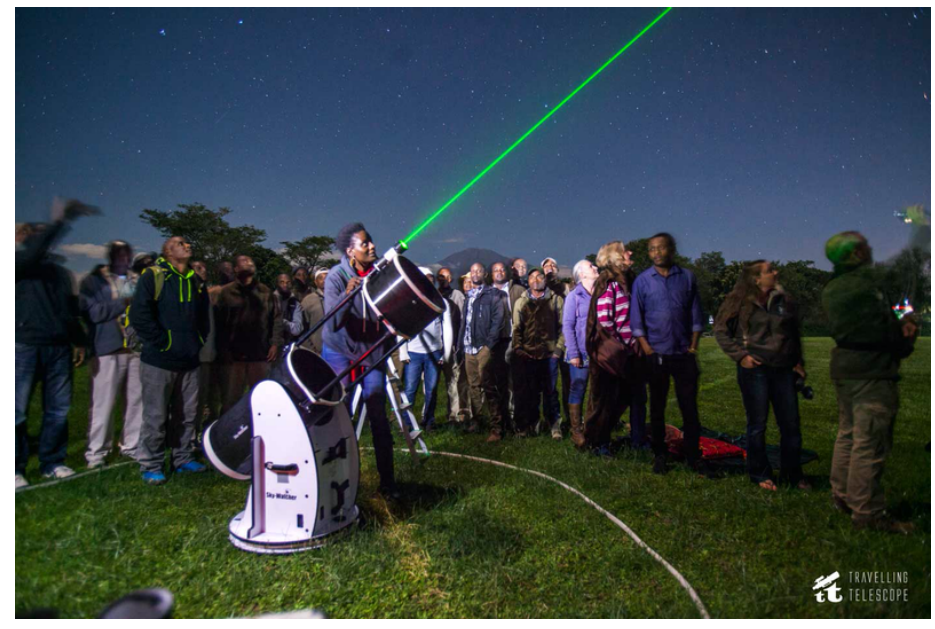

Murabana shows visitors the night sky at a Travelling Telescope event.

Credit: D. C. Owen/The Travelling Telescope

\section{You did some of the building work yourself. How was that?}

Yes. My partner, I, and our team-astronomy graduates from the local university-helped treat the bamboo and bind it into triangles for the geodesic dome. It took many months of researching, planning, and calculating before we even dealt with the bamboo. It was a lot of work. Once the dome frame was complete, we were so proud of what we'd done. It was really a moment of "wow, we've done this, we've built this."

\section{How has the planetarium been received?}

There has been lots of interest and excitement. We had our first show in January, and it sold out within an hour. But then the COVID-19 pandemic hit, and the planetarium had to shut, as the government rules prohibit large crowds. We also stopped touring with our portable planetarium, as we can't go into schools.

In August, my partner and I spoke about the Nairobi

Planetarium at the International Planetarium Society meeting, and everyone expressed excitement about the new building. At that meeting, we had the idea of redesigning the structure to be better ventilated and safer during the pandemic. We are now in the process of doing that.

As well as working on the Travelling Telescope, you are also president of the African Planetarium Association. Can you tell me about what you do there?

The Association supports planetariums across the continent, developing and sharing resources and fostering collaborations among people working on similar science education efforts. It also works to expand the number of planetariums in Africa to make these educational opportunities more widely available.

The Association supports grants awarded to planetarium projects by the Office of Astronomy for Development, an organization that promotes astronomy around the world. For example, one project we are currently involved in is one in Algeria, where an astronomy club is creating planetarium shows in Arabic as part of its outreach program, the Constantine Cosmos Caravan. These are the kinds of things we want to do as an association-promote Africa by creating something unique that we can share with the rest of the world.

\section{What are your future hopes for astronomy engagement in Africa?}

My dream is to get every child at least one astronomy lesson under the African skies. The telescope was invented more than 400 years ago, but most people have never looked through one. And yet, seeing the skies through a telescope has the power of changing our perspective of life, of our health, and of the environment by showing us the beauty of nature.

Erika K. Carlson is a Corresponding Editor for Physics based in New York City. 